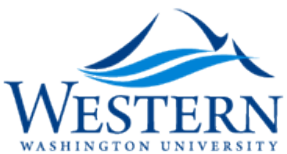

Western Washington University

Western CEDAR

$1-2012$

\title{
Revisiting the Thetic/Categorical Distinction in Japanese
}

Masanori Deguchi

Western Washington University, Masanori.Deguchi@wwu.edu

Follow this and additional works at: https://cedar.wwu.edu/mcl_facpubs

Part of the Japanese Studies Commons

\section{Recommended Citation}

Deguchi, Masanori, "Revisiting the Thetic/Categorical Distinction in Japanese" (2012). Modern \& Classical Languages. 51. https://cedar.wwu.edu/mcl_facpubs/51

This Article is brought to you for free and open access by the Humanities at Western CEDAR. It has been accepted for inclusion in Modern \& Classical Languages by an authorized administrator of Western CEDAR. For more information, please contact westerncedar@wwu.edu. 


\title{
REVISITING THE THETIC/CATEGORICAL DISTINCTION IN JAPANESE
}

\author{
MASANORI DEGUCHI \\ Western Washington University \\ masanori.deguchi@wwu.edu
}

\begin{abstract}
In this study, I propose a refinement of Kuroda's (1972, 1990) claim that the categorical and thetic judgments are realized syntactically in Japanese. Succinctly put, Kuroda argues that sentences with the topic marker wa represent categorical judgments whereas those with the nominative marker $g a$ represent thetic judgments. In the present study, I demonstrate that wa-sentences do not uniformly represent categorical judgments and that $g a$-sentences do not represent thetic judgments across the board either. In particular, I argue that $g a$-sentences represent thetic judgments only on the so-called "neutraldescription" reading (in the sense of Kuno 1973); on the "exhaustive-listing” reading, they instead involve categorical judgments. In addition, I demonstrate that wa-sentences also require a parallel refinement: thematic $w a$ vs. contrastive $w a$. I therefore propose a four-way distinction and further demonstrate that the four readings are interrelated through different types of judgments as follows: thematic wa and exhaustive-listing $g a$ involve categorical judgments whereas contrastive wa and neutral-description ga involve thetic judgments.
\end{abstract}

KEYWORDS: Thetic and categorical judgments; Japanese wa and ga; contrastive reading; exhaustive-listing reading.

\section{Introduction*}

Kuroda $(1972,1990)$ demonstrates that different types of judgments manifest themselves syntactically in Japanese. More specifically, adopting the Brentano-

\footnotetext{
* I would like to thank the two anonymous reviewers for their constructive comments. My sincere thanks are also due to Shannon Dubenion-Smith, who proofread the manuscript and provided insightful feedback.
} 
Marty theory of judgment (cf. Marty (1965), Kuroda argues that sentences marked with the so-called topic marker wa represent categorical judgments while ones marked with the nominative marker ga represent thetic judgments (henceforth $w a$-sentences and $g a$-sentences, respectively). ${ }^{1}$

I demonstrate in this paper that close examination of Japanese data makes it necessary to make finer distinctions than Kuroda's dichotomy between $w a-$ sentences and ga-sentences. Specifically, I argue that $g a$-sentences represent thetic judgments only on the so-called "neutral-description" reading and that $w a$-sentences represent categorical judgments only on the "thematic" reading in the sense of Kuno (1973).

The rest of the paper is organized as follows. In Section 2, I recapitulate the basic ideas of the Brentano-Marty theory of judgment as summarized in Kuroda (1972) and discuss Kuroda's adaptation of these in Japanese. I focus on summarizing Kuroda's main claims and clarifying his rationale behind them. In Section 3 , I demonstrate that $w a$-sentences do not represent categorical judgments uniformly (Section 3.1) and that ga-sentences do not represent thetic judgments uniformly, either (Section 3.2). I lend support to this proposal in Section 3.3 and discuss its implications in Section 3.4. Section 4 concludes the paper.

\section{The Brentano-Marty theory of judgment in Japanese}

Traditional logic only recognizes one type of judgment: a judgment that involves the subject and the predicate (cf. Kneale and Kneake 1964). As Kuroda (1972: 153) points out, it is Frege who questioned this fundamental premise in traditional logic and disposed of the distinction between the subject and predicate. The transition from traditional to modern logic thus opened the door to a different type of judgment, a judgment without a subject. This "subjectless" judgment is called the "thetic" judgment in the theory proposed by Franz Brentano, on which Anton Marty later elaborated. A judgment with a subject is, in contrast, called the "categorical" judgment. Typical thetic sentences include existential sentences (1a), impersonal sentences (1b), and "universal” sentences (1c); examples of categorical sentences include those in (2). The German exam-

\footnotetext{
${ }^{1}$ A similar opposition is discussed in Kuroda (1965), where he calls the two types of judgments the "predicational judgment" (cf. the categorical judgment) and the "non-predicational description" (cf. the thetic judgment), respectively. As Kuroda (1990) notes in his introduction, he couched the wa/ga distinction in the Brentano-Marty theory of judgment for the first time in the early seventies. While occasional references will be made to Kuroda (1965), I will focus on Kuroda (1972 and his subsequent work) in the rest of the paper.
} 
ples are from Kuroda (1972: 154) with the English glosses and translations added.

(1) Sentences involving the thetic judgment

(1a) Gott ist.

God is

'God exists.'

(1b) Es regnet. ${ }^{2}$

it rains

'It rains/it is raining.'

(1c) Alle Dreiecke haben zur Winkelsumme zwei Rechte. all triangles have to angle.sum two right 'All triangles have internal angles equal to the sum of two right angles.'

(2) Sentences involving the categorical judgment

(2a) Ich urteile.

I judge

'I judge/I am judging.'

(2b) Der Körper ist auf der Erde. the body is on the earth 'The body is on the earth.'

(2c) Dieses Pferd ist ein Schimmel. this horse is a white.horse 'This horse is a white horse.'

Before I discuss the above examples, a terminological note is in order. It is crucial to make a distinction between two notions of the subject: the subject of a sentence (i.e., the grammatical notion) and the subject of judgment (i.e., the psychological notion). While the sentences in (1) involve "subjectless" judgments (i.e., thetic judgments), they have grammatical subjects, as do the sentences in (2). For example, Gott 'god' is the grammatical subject in (1a) in the same sense that ich ' $\mathrm{I}$ ' is the grammatical subject in (2a). The crucial difference between the thetic sentences in (1) and the categorical sentences in (2) is that

\footnotetext{
${ }^{2}$ As there is no separate progressive form in German, sentences like (1b) (and also (2a)) are ambiguous between habitual and progressive interpretations.
} 
judgments are made on entire sentences in the former whereas they are made on grammatical subjects in the latter. In other words, while all sentences make the grammatical distinction of subject and predicate, they may or may not evoke the subject in terms of judgment. To make the relevant distinction clear, I use the terms grammatical subject and the subject of judgment throughout this paper.

Keeping the basic ideas of the Brentano-Marty theory in mind, let us now turn to Kuroda's $(1972,1990)$ adaptation of them in Japanese. In a nutshell, Kuroda argues that $w a$-sentences represent categorical judgments whereas gasentences represent thetic judgments. Let us discuss the observations based on which he makes his claims.

Kuroda first points out that virtually every sentence in English translates into two distinct yet related sentences in Japanese, as illustrated in (3) and (4).

(3) Japanese translations of $A$ dog is running [Kuroda (1972: 161)]

(3a) Inu-ga hashitte iru. dog-NOM running is

(3b) Inu-wa hashitte iru. dog-TOP running is

(4) Japanese translations of A dog is chasing a cat [Kuroda (1972: 161)]

(4a) Inu-ga neko-o oikaket iru. dog-NOM cat-ACC chasing is

(4b) Inu-wa neko-o oikakete iru. dog-TOP cat-ACC chasing is

Both the $a$ and $b$ sentences are possible translations in Japanese. One of the crucial differences between them is in the marking of the grammatical subject; It is marked with the nominative case marker $g a$ in the $a$ sentences but the so-called "topic" marker wa in the $b$ sentences.

The other crucial difference that Kuroda points out is the way in which the participants contribute to the event expressed by the predicate. For example, when a Japanese speaker notices an event where a dog is chasing a cat, $\mathrm{s} /$ he will describe it with a ga-sentence like (4a), not with a wa-sentence like (4b). Since oikakeru 'to chase' is a transitive verb, the event of chasing necessarily involves two participants, “the chaser” (inu 'a dog,' realized as the grammatical subject) and "the chased" (neko 'a cat,' realized as the grammatical object). While the speaker recognizes these participants, his/her attention is not drawn to the par- 
ticipants. Instead, the attention is directed toward the event itself. ${ }^{3}$ To verify this point, compare (4a) with its scrambled counterpart in (5a).

(5) Scrambled counterparts of (4) (Kuroda 1972: 164)

(5a) Neko-o inu-ga oikakete iru. cat-ACC dog-NOM chasing is

(5b) ??Neko-o inu-wa oikakete iru. cat-ACC dog-TOP chasing is

The grammatical subject (inu-ga 'a dog-NOM') and the grammatical object (neko-o 'a cat-ACC') are scrambled in (5a). Observe that the scrambled sentence in (5a) is equally acceptable to the unscrambled counterpart in (4a). Kuroda takes this observation as evidence that the speaker's attention is not directed toward either of the participants; it is instead directed toward the event itself.

Let us now turn to (4b), a wa-sentence. As noted above, Japanese speakers will not use the $w a$-sentence in (4b) when they notice the event of a dog chasing a cat. The wa-sentence like (4b) is instead used when specifying what the dog is doing. In other words, the speaker's attention is directed toward the dog, the participant expressed by the wa-phrase. Now compare the wa-sentence in (4b) with its scrambled counterpart in (5b). As Kuroda (1972: 164) observes, (5b) is "markedly unnatural, if acceptable at all." ${ }^{4}$ Given the fact that the grammatical subject and object cannot be scrambled with wa-sentences like (5b), it is reasonable to claim that a wa-marked argument and other arguments have a different status. In addition, provided that a "prominent" argument linearly precedes a "non-prominent” one as Choi (1999: 97) claims, the marginal status of (5b) allows us to support the idea that a wa-phrase has a prominent status toward which the speaker's attention is directed.

In sum, when using a ga-sentence, the speaker's attention is directed toward the event in its entirety despite the fact that the sentence involves a partition be-

\footnotetext{
${ }^{3}$ Lambrecht (1994) calls the type of information structure represented in the ga-sentences in (3) and (4) "sentence-focus" because the domain of focus corresponds to the entire proposition expressed by the sentence. Because of the common communicative function of such a sentence type, ga-sentences as in (3) and (4) are also called "event-reporting” sentences or "neutral-description" sentences. In Section 3.1, this type of $g a$-sentence will be contrasted with another type: "exhaustive-listing” (Kuno 1973).

${ }^{4}$ The acceptability of (5b) improves if the scrambled phrase (i.e., neko-o 'a cat-ACC') is emphasized. There is, however, a clear contrast between (5a) and (5b) since the former is acceptable without such emphasis.
} 
tween the grammatical subject and the predicate. Kuroda $(1972,1990)$ therefore argues that $g a$-sentences represent "subjectless" judgments (i.e., the thetic judgment). In contrast, in wa-sentences, the speaker's attention is drawn toward the participant expressed by the wa-phrase, and the action expressed by the predicate is attributed to it. Kuroda therefore claims that $w a$-sentences represent "judgments with subject" (i.e., the categorical judgment), and that the wa-phrase is the subject of judgment. ${ }^{5}$

Kuroda's $(1972,1990)$ claims are summarized in (6).

(6) Summary of Kuroda's claims

(6a) $G a$-sentences represent thetic judgments.

(6b) Wa-sentences represent categorical judgments.

(6c) The wa-phrase is the subject of the categorical judgment.

Kuroda argues that the thetic and categorical judgments in Japanese are realized syntactically in a distinct manner; categorical sentences involve a wa-phrase (6b) whereas thetic sentences involve a $g a$-phrase (6a). ${ }^{6}$ In addition, he claims that the subject of the categorical judgment is realized in the form of a wa-phrase (6c).

\section{Proposals}

In this section, I demonstrate that ga-sentences may represent either a thetic judgment or a categorical judgment, depending on the reading involved (Section 3.1); similarly, wa-sentences may represent a thetic judgment as well as a categorical judgment, depending on the reading (Section 3.2).

\subsection{Two types of $g a$-sentences}

Kuno (1973: Ch.2) discusses two distinct readings of ga-sentences: "exhaustivelisting” ga and "neutral-description” ga. Exhaustive-listing ga is used in ques-

\footnotetext{
${ }^{5}$ In Japanese, not only the grammatical subject but also other constituents can be marked with wa, including postpositional phrases. Given this fact, the subject of judgment is not necessarily the grammatical subject. Consequently, the distinction between the grammatical subject and the subject of judgment is crucial, as noted in Section 1.

${ }^{6}$ To be precise, the categorical vs. thetic distinction corresponds to the wa vs. non-wa distinction rather than the wa vs. ga distinction (Kuroda (1990: 79)). Observe that it is possible for a Japanese sentence to have neither wa nor $g a$ (e.g., Inu-mo hashitte iru 'A dog is also running'). For ease of exposition, I continue to refer to the distinction as wa vs. ga.
} 
tion-answer pairs like (7); sentences like (7b) would be marginal in isolation.

(7) Exhaustive-listing ga

(7a) Q: Dare-ga gengogaku-o senkoosite iru-no. who-NOM linguistics-ACC majoring is-Q 'Who is majoring in linguistics?'

(7b) A: Taroo-ga (gengogaku-o) senkoosite iru. Taro-nom linguistics-acc majoring is.

'Taro is majoring (in linguistics).'

What is implied in the response in (7b) is that Taro is the one and only one person (in the given context) who is majoring in linguistics. Since this answer exhausts the list of people that fit the description expressed by the predicate, the reading illustrated in (7b) is called the exhaustive-listing reading. In contrast, the sentences in (8) are said to have a neutral-description reading.

(8) Neutral-description ga [Kuno (1973: 50)]

(8a) Ame-ga hutte iru.

rain-NOM falling is

'Rain is falling.' (i.e., 'It is raining.')

(8b) Sora-ga akai.

sky-NOM red

'The sky is red.'

While the sentences in (8) are as grammatical as that in (7b), they do not typically serve as responses to questions such as those in (9). ${ }^{7}$

(9a) Nani-ga hutte iru-no.

what-NOM falling is-Q

'What is falling?'

(9b) Nani-ga akai-no.

what-NOM red-Q

'What is red?'

\footnotetext{
${ }^{7}$ The sentences in (8) can function as responses to those in (9), but only if the ga-phrase is emphatically stressed. It is crucial to note here that exhaustive-listing sentences like (7b) do not involve such emphatic stress. It is therefore important, when evaluating the sentences, not to stress the gaphrase.
} 
This is because (8a) does not mean that it is rain and only rain that is falling; similarly, (8b) does not mean that it is the sky and only the sky that is red. Instead, the $g a$-sentences like (8a) and (8b) describe situations/events; hence, the name "(neutral-)description" (of an event).

What is interesting and crucial in the ensuing discussion is the fact that exhaustive-listing $g a$-sentences can be paraphrased using $w a$, whereas neutraldescription ga-sentences cannot (Kuroda 1965: Ch. 2). Compare (10) and (11).

(10) Paraphrase of exhaustive-listing ga-sentence (cf. 7b)

Gengogaku-o senkoosite iru-no-wa Taroo desu.

linguistics-ACC majoring is-nominal-TOP Taro is

'It is Taro who is majoring in linguistics.'

(11) Apparent paraphrases of neutral-description ga-sentences [cf. (8)]

(11a) Hutte iru-no-wa ame desu.

falling is-NOMINAL-TOP rain is

'What is falling is rain.'

(11b) Akai-no-wa sora desu.

red-NOMINAL-TOP sky is

'What is red is the sky.'

As illustrated in (10), ga-sentences on the exhaustive-listing reading can be paraphrased using wa. Also, notice that the wa-paraphrase in (10) has retained the exhaustive-listing reading in (7b), as the English translation indicates. In contrast, ga-sentences on the neutral-description reading like (8) do not lend themselves to wa-paraphrases. Their apparent paraphrases are given in (11). Since the meanings have been changed from (8) to (11) as the English translations show, $g a$-sentences on the neutral-description reading cannot be paraphrased with wa. The presence vs. absence of wa-paraphrases thus allows us to argue for two types of ga-sentences.

Now recall from (6c) that Kuroda $(1972,1990)$ claims that a wa-phrase is the syntactic manifestation of the subject of categorical judgments. Since gasentences on the exhaustive-listing reading can be paraphrased with $w a$, I argue that $g a$-sentences on the exhaustive-listing reading represent categorical judgments although there is no wa-phrase on the surface. I therefore propose that Kuroda's claim in (6a) be modified as in (12). 
(12) Proposals (to be expanded)

(12a) $G a$-sentences on the neutral-description reading represent thetic judgments.

(12b) $G a$-sentences on the exhaustive-listing reading represent categorical judgments.

While Kuroda $(1970,1990)$ claims that $g a$-sentences represent thetic judgment across the board, I argue that $g a$-sentences represent thetic readings only on the neutral-description reading (12a); ga-sentences instead represent categorical judgments on the exhaustive-listing reading (12b). In other words, I propose that a third type of judgment be recognized: categorical judgment on $g a$-sentences. ${ }^{8}$

In the next section, I propose a distinction parallel to that in (12) for wasentences, rendering a four-way distinction. In addition, I further demonstrate that $g a$-sentences on a specific reading are linked to $w a$-sentences on a specific reading in terms of judgment.

\subsection{Two types of wa-sentences}

In Section 3.1, I motivated the need for recognizing two types of ga-sentences in terms of judgment. Let us now turn our attention to $w a$-sentences in a similar vein.

Kuno (1973: Ch.2) discusses two distinct readings of wa-sentences: the "thematic" reading and the "contrastive” reading, as illustrated in (13). ${ }^{9}$

\footnotetext{
${ }^{8}$ Kuroda (1965: 50) also discusses a third type of judgment. He illustrates this judgment with an example like (i) [Kuroda’s (66)].

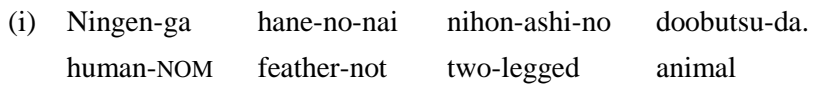

'A human is a featherless biped.'

He calls this a "characterizational judgment" since the noun marked by ga is characterized by the property expressed by the predicate.

While it is possible that the proposal in (12b) is essentially the same as the characterizational judgment, the theory of judgment I propose is crucially different from Kuroda's as I will, in addition, recognize a fourth type of judgment in Section 3.2: the thetic judgment on wa-sentences.

${ }^{9}$ I only discuss wa used on the grammatical subject. See Deguchi (2003: 142-146) for a discussion of wa used on the direct object and the effect of scrambling and that of emphatic stress on its interpretations.
} 
(13) Two readings of wa [Kuno (1973: 38)]

(13a) John-wa sono hon-o yonda.

John-TOP the book-ACC read

'Speaking of John, he read the book.'

(13b) Ame-wa hutte iru.

rain-TOP falling is

'It is raining, (but).'

The wa-sentence in (13a) illustrates the thematic reading, where the "topic," John, is described as having read a book. ${ }^{10}$ In contrast, the wa-sentence in (13b) illustrates the contrastive reading, where the event of raining is contrasted with another possible event (e.g., the event of not raining). The contrastiveness in (13b) can be further verified by the fact that such a sentence sounds "unfinished" and thus marginal unless it is in a contrastive context, as shown in (14).

\begin{tabular}{|c|c|c|c|}
\hline (14a) & $\begin{array}{l}\text { Ame-wa hutte iru } \\
\text { rain-TOP falling is } \\
\text { 'It is raining, but...' }\end{array}$ & $\begin{array}{l}\text { ga... } \\
\text { but }\end{array}$ & \\
\hline (14b) & $\begin{array}{lll}\text { Ame-wa } & \text { hutte } & \text { iru } \\
\text { rain-TOP } & \text { falling } & \text { is }\end{array}$ & $\begin{array}{ll}\text { ga, } & \text { sugu } \\
\text { but } & \text { soon }\end{array}$ & $\begin{array}{l}\text { yami-sooda } \\
\text { stop-seem }\end{array}$ \\
\hline
\end{tabular}

In (14a), the contrastive context is provided by ga 'but.' The exact contrast is just implied and is left open. In (14b), the contrastive context is spelled out. Since wa-sentences like (13b) must be in a contrastive context, the reading illtrated therein is a contrastive reading. On the other hand, there is no such contrast associated with thematic readings as in (13a). ${ }^{11}$

\footnotetext{
${ }^{10}$ Here, "topic" is taken as information identifiable in the discourse, whether it is already mentioned or it is always uniquely identifiable (e.g., the moon). See Kuno (1973: Ch.2) for discussion.

${ }^{11}$ Kuno (1973: 47) observes that wa-sentences like (13a) are ambiguous and can be construed as contrastive. It is true that the kind of contrastiveness that can be detected in (13a) can be more pronounced in a sentence like (ii) (Kuno's (22b)).

(ii) John-wa sono hon-o yonda ga, Mary-wa yomanakatta. John-TOP the book-acc read but Mary-TOP read.not

'John read the book, but Mary didn't.'

However, there are few crucial differences between the contrastiveness observed in (13a)/(ii) and that in (13b). First, unlike the contrastive sentence in (13b), the thematic sentence in (13a) sounds
} 
The difference between thematic wa and contrastive wa seems to run parallel to the difference between exhaustive-listing $g a$ and neutral-description $g a$. With a contrastive $w a$-sentence, we saw that the attention of the speaker is directed toward the event itself (e.g., the event of raining, not the rain itself in (13b)). In other words, the speaker is not attributing the meaning of the predicate (i.e., falling) to the participant expressed by the wa-phrase (i.e., rain) in (13b). This seems parallel to ga-sentences on the neutral-description reading. Given this similarity between the contrastive $w a$ and the neutral-description $g a$, I expand the proposals in (12) as shown in (15).

(15) Proposals (final)

(15a) $\quad G a$-sentences on the neutral-description reading represent thetic judgments. (=(12a))

(15b) $G a$-sentences on the exhaustive-listing reading represent categorical judgments. $(=(12 b))$

(15c) Wa-sentences on the contrastive reading represent thetic judgments.

(15d) Wa-sentences on the thematic reading represent categorical judgments.

Based on the similarity with neutral-description $g a$, I claim that wa-sentences represent thetic judgments on the contrastive reading as in (15c), contrary to Kuroda. Regarding $w a$-sentences on the thematic reading, I assume with Kuroda that they represent categorical judgments as in (15d).

In Section 3.3, I provide evidence in support of the two crucial differences between the proposals in (15) and those of Kuroda in (6). The two differences are summarized in (16).

Two crucial differences

(16a) Two types of wa-sentences and two types of $g a$-sentences exist in terms of different types of judgments.

finished in isolation. Second, what is contrasted is different in the two cases. In (ii), an argument (i.e., John) is contrasted with another argument (i.e., Mary). On the other hand, the entire proposition is contrasted with another (possible) proposition in (13b). I call the former type of contrastiveness "contrastive theme" and would like to reserve the label "contrastive reading (without qualification)" for the latter type exemplified in (13b).

In addition, when a wa-phrase as in (13a) is emphatically stressed, contrastiveness arises as in (iii).

(iii) JOHN-wa sono hon-o yonda.

John-TOP the book-ACC read

'John read the book, but (e.g., Mary didn't).'

However, the contrast in (iii) is also that of contrastive theme. 
(16b) In addition, neutral-description $g a$ and contrastive wa represent the same judgment (i.e., thetic), and exhaustive-listing ga and thematic wa represent the same judgment (i.e., categorical).

\subsection{Support}

What is interesting about the distinct readings of $w a$ and those of $g a$ is that the contrastive reading of $w a$ arises in the same environments as those for the neutral-description reading of ga. Deguchi (2008) observes that wa-sentences obligatorily receive the contrastive reading when their $g a$-sentence counterparts receive the neutral-description reading as illustrated in (17) and (18).

Ame-ga hutte iru. $\quad \quad(=(8 a)$; neutral-description $)$
rain-NOM falling is
'It is raining.'
Ame-wa hutte iru. $\quad(=(13 b)$; contrastive $)$
rain-TOP falling is
'It is raining, (but).'
(18a) Atama-ga itai. (neutral-description) head-NOM painful 'I have a headache.'
(18b) Atama-wa itai. (contrastive) head-TOP painful 'I have a headache, (but).'

As was confirmed with (8a), the ga-sentence in (17a) only allows for the neutral-description reading. Observe that its wa-sentence counterpart in (17b) only allows for the contrastive reading. ${ }^{12}$ The same correlation between the neutraldescription reading of $g a$ and the contrastive reading of $w a$ is also shown in (18). If the correlation in (17) and (18) is correct, it is predicted that there is a correlation between the thematic reading of $w a$ and the exhaustive-listing reading of ga as well. This prediction is in fact borne out, as illustrated in (19) and (20).

\footnotetext{
${ }^{12}$ One of the reviewers brought to my attention the fact that the contrastive reading as in (17b) noticeably weakens when the sentence is negated. I agree with the reviewer on the judgment. However, I am yet to have an explanation why that is the case.
} 
John-wa sono hon-o yonda. (=(13a); thematic)

John-TOP the book-ACC read

'Speaking of John, he read the book.'

(19b) John-ga sono hon-o yonda. (exhaustive-listing)

John-nom the book-ACC read

'It is John who read the book.'

(20a) Kujira-wa honyuu-doobutsu da

(Kuno 1973: 44) whale-TOP mammal is

'Speaking of whales, they are mammals.'

(20b) Kujira-ga honyuu-doobutsu da

whale-TOP mammal is

'It is whales that are mammals.'

We saw that the $w a$-sentence in (13a), repeated here as (19a), only has the thematic reading. Its ga-sentence counterpart in (19b) only has the exhaustivelisting reading as indicated in the English translation. Similarly, the predication is borne out in (20) as well.

The observations in (17) through (20) thus support the two points summarized in (16). They support the claim that $w a$-sentences as well as $g a$-sentences represent two distinct types of judgment. In addition, not only are there two types of judgment for $g a$-sentences and also for $w a$-sentences, they are related to each other, as summarized in (21).

(21) Relationships between $g a$-sentences and $w a$-sentences

(21a) Neutral-description $g a$ and contrastive $w a \rightarrow$ Thetic judgment

(21b) Exhaustive-listing ga and thematic $w a \rightarrow$ Categorical judgment

\subsection{Implications}

One of the implications of the proposals in (15) is that Kuroda's proposal in (6c), repeated as (22a), must be modified as in (22b).

(22) Implications

(22a) The wa-phrase is the subject of the categorical judgment. (=(6c))

(22b) The wa-phrase on the thematic reading is the subject of the categorical judgment. 
(22c) The ga-phrase on the exhaustive-listing reading is the subject of the categorical judgment.

If $w a$-sentences on the contrastive reading involve thetic judgments (i.e., "subjectless" judgments) as argued above, it follows that wa-sentences have the subject of judgment only on the thematic reading. In addition, if ga-sentences on the exhaustive-listing reading involve categorical judgments as evidenced by the presence of $w a$-paraphrases, the ga-phrase in an exhaustive-listing sentence is also a subject of judgment. This latter modification is given in (22c).

\section{Conclusion}

I demonstrated in Sections 3.1 and 3.2 that ga-sentences and wa-sentences do not uniformly represent thetic judgments and categorical judgments respectively, contrary to Kuroda's $(1972,1990)$ claim. I also demonstrated that gasentences on the exhaustive-listing reading represent categorical judgments in spite of the absence of a wa-phrase on the surface. A parallel distinction was motivated for wa-sentences in Section 3.2.; wa-sentences on the contrastive reading involve thetic judgments despite the presence of a wa-phrase, which Kuroda $(1972,1990)$ claims to be the grammatical manifestation of the subject of (the categorical) judgment.

In sum, I have proposed a four-distinction among ga-sentences and $w a$ sentences, as opposed to Kuroda's two-way distinction. I have supported the four-way distinction based on the correlations among different readings of $g a-$ sentences and $w a$-sentences. One of the implications is that, contrary to Kuroda's claim, a wa-phrase does not necessarily represent the subject of judgment (see (22b) and (22c)). In this respect, Kuroda's claim is tenable only in a weaker form. 


\section{REFERENCES}

Choi, H.-W. 1999. Optimizing structure in context: Scrambling and information structure. Stanford: CSLI Publications.

Deguchi, M. 2008. “Topicalization and contrastive readings: Insights from Japanese wa.” Paper presented at the 30th Annual Conversion of the German Linguistics Society. University of Bamberg, Bamberg, Germany.

Deguchi, M. 2003. The anatomy of quantifier scope interaction. (PhD dissertation, Indiana University, Bloomington.)

Kneale, W. and M. Kneale. 1964. The development of logic. Oxford: Clarendon Press. Kuno, S. 1973. The structure of the Japanese language. Cambridge, MA: MIT Press.

Kuroda, S.-Y. 1965. Generative grammatical studies in the Japanese language. (PhD dissertation, MIT.)

Kuroda, S.-Y. 1972. "The categorical and the thetic judgment: Evidence from Japanese syntax.” Foundations of Language 9. 153-185.

Kuroda, S.-Y. 1990. “The categorical and the thetic judgment reconsidered.” In: Mulligan, K. (ed.), Mind, meaning and metaphysics. Cambridge: Kluwer Academic Publishers. 77-88.

Lambrecht, K. 1994. Information structure and sentence form: Topic, focus and the mental representations of discourse referents. Cambridge: Cambridge University Press.

Marty, Anton. 1965. Psyche und Sprachstruktur. Bern: Francke.

\section{Address correspondence to:}

Masanori Deguchi

Department of Modern and Classical Languages

Western Washington University

516 High Street, MH 223

Bellingham, WA 98226

USA

masanori.seguchi@wwu.edu 